\title{
Genetic and epigenetic etiology of autoimmune diseases: lessons from twin studies
}

\author{
Saeed Aslani' ${ }^{1}$ Ramazan Rezaei ${ }^{1,2}$, Ahmadreza Jamshidi ${ }^{1}$, Mahdi Mahmoudi ${ }^{\text {* }}$ \\ ${ }^{1}$ Rheumatology Research Center, Tehran University of Medical Sciences, Tehran, Iran; ${ }^{2}$ Department of Immunology, School of \\ Medicine, Tehran University of Medical Sciences, Tehran, Iran
}

\begin{abstract}
Twin studies have been considered as strong approaches in determining the cause of complex diseases with regard to identifying the involvement of multiple genes, single genes, environmental factors, and a possible relation between genetics and the environment. The concordance observed among monozygotic (MZ) twins suggests the involvement of genetic factors. Nonetheless, MZ twins demonstrate a rate of discordance in different characteristics, like proneness towards diseases, despite virtually identical genetic backgrounds. Discordance has been suggestive of the involvement of the environment alongside genetic factors. As a result, a bulk of studies has supported the hypothesis that environmental factors can impress the epigenetic construction and, therefore, influence disease susceptibility. Twin studies yield data about clinical courses and outcomes of disease, in addition to knowledge of genetics, epigenetics, environmental factors, and risk of disease development. To date, genome-wide association studies (GWASs) have reported that genomic variants are responsible for only a number of cases of autoimmunity in twins and have been unable to explain the disease discordance among MZ twins. With respect to the exploration of epigenetic mechanisms in autoimmunity, discordant MZ twins have been attractive models and have contributed remarkably. It is essential for future studies to evaluate the genetic variants as well as epigenetic changes in large twin populations. The current review discusses the genetic and epigenetic lessons obtained from studies of twin cases.
\end{abstract}

Keywords: environmental factors, epigenetic changes, genetic factors, monozygotic twins.

\section{Introduction}

Twin cases are regarded as precious facilities, which contribute to discriminating the causal mechanisms of disease, mediated by genetic or environmental factors [1, 2]. Twin cases can be applied by comparing the disease concordance/discordance between monozygotic twins (MZ, or identical twins) and dizygotic twins (DZ, or fraternal twins). In MZ twins, it is assumed that both individuals share $100 \%$ of their genomic sequences. Moreover, the higher phenotypic concordance rate of $\mathrm{MZ}$ twins in comparison to DZ twins implies to predominant influence of the genetic background, while environmental factors are concluded to have a greater role if concordance rates are low.

Oftentimes, the concordance rates are resultant of both genetic and environmental factors, which vary in degrees of influence. Among the environmental factors are microorganisms, chemicals and drugs, and lifestylerelated factors, such as diet and exercise [3]. In combinations of genetic and environmental factors, genetically susceptible individuals are exposed to environmental agents over and over again throughout life, which ultimately eventuates in disease initiation. This scenario occurs in multifactorial disease, such as autoimmune disorders, which are supported through a weak applicability of strong genetic associations obtained from GWASs [4].

It should be noted that $\mathrm{MZ}$ twins demonstrate a concordance rate between $5 \%$ and $75 \%$, which is 2 to 5 times higher than DZ twins [5]. However, discordance rate is the other side of the coin. In some disorders, a certain mutation is exclusively the cause of the bad outcome, which might occur as somatic mutation during embryonic development. Nonetheless, in case of no mutation is identified in association with the disease, it is suggested that the discordance might be the consequence of epigenetic changes at the locus attributed with the disease pathogenesis. As a result, the discordance observed in the disease occurrence of MZ twins could be explained through the collaboration of external (environmental) factors that impress disease

\footnotetext{
* Corresponding Author: Mahdi Mahmoudi, E-mail: mahmoudim@tums.ac.ir, Tele-fax: +98-218-822-0067, PO-BOX: 1411713137 Received: 21 October 2017; Accepted: 24 October 2017
} 
predisposition by modifying the epigenome profile that finally determines the function of genes [6].

This review will discuss the current understanding of typical inflammatory autoimmune diseases with respect to genome and epigenome highlights, including rheumatoid arthritis (RA), systemic lupus erythematosus (SLE), systemic sclerosis (SSc), Ankylosing Spondylitis (AS), and Psoriasis.

\section{Twin studies in autoimmune diseases}

Numerous factors have been implicated in autoimmune disorders, including clinical manifestations, gender, age, genetic predisposing factors, race, geoepidemiology, and etiology. Evaluating the etiopathogeneses of autoimmune disorders in twin cases has shown that there is a contributing genetic component to these diseases with concordance rates varying between $75 \%$ to $83 \%[7,8]$. However, in some other autoimmune conditions like SSc and RA, the role of genetic factors seems to be less significant, and other elements such as environmental factors may be highlighted [9-12]. Although studies may investigate identical populations, they might observe conflicting findings. This may be due to the circumstances of the studies like sample size, limited follow-up or screening of data, a lack of sufficient clinical data, and unsuitable twin determinants. Furthermore, twin studies have largely been case reports with fewer cohort evaluations of twin populations. On the other hand, epigenetic marks seem to be emerging factors affecting the concordance rates of such diseases. In a remarkable proportion of identical twins with autoimmune disorders, one twin remains unaffected, implying that other determinants such as environmental factors and epigenetic modifications may also play a role.

\section{Genetic implications \\ Rheumatoid arthritis}

Genetic association studies of twins with RA have elucidated a lower level of concordance in MZ twins, proposing a lower degree of genetic involvement in RA compared with other autoimmune diseases. Lawrence reported an RA concordance of 30\% [13]. However, a broad Finnish cohort study of $4136 \mathrm{MZ}$ and $9162 \mathrm{DZ}$ twins demonstrated an RA concordance of $12.3 \%$ among MZ twins, and a DZ twin concordance of 3.5\% [9]. A high level of concordance has been shown in a 1980 Australian twin cohort study which included 3808 pairs of twins [14]. Another cohort study of 186 twins conducted in 1990 described an RA prevalence rate of $0.4 \%$ among $\mathrm{MZ}$ and DZ twins. Pairwise concordance rates were $21 \%$ and $0 \%$ in $\mathrm{MZ}$ and DZ twins, respectively [14]. The exact mechanisms of the concordance rate could not be determined, because there was an $89 \%$ false positive proportion of self-reporting RA according to the questionnaire [14]. This indicates that the application of questionnaires in twin studies is limited by the probable lack of clinical verification. Slightly lower rates of twin concordance (3.6\% in DZ and $15.4 \%$ in $\mathrm{MZ}$ twins) were reported in a UK cohort study [11]. However, the sample size of that study included $112 \mathrm{DZ}$ and $91 \mathrm{MZ}$ twins, fewer subjects than the Finnish cohort study. A UK cohort study described that the initial discordance between twins became concordant over time [11]. Furthermore, the risk of developing RA in an initially unaffected twin group was increased over time, implying that overall concordance rates in autoimmune diseases such as RA with obvious clinical manifestations expanded over several years. As a result, it is critical to describe the concordance rate only after prolonged and full follow-up [11]. Such cases provide evidence that the development of RA in pairs may occur with delayed time, implicating the function of non-genetic factors. Some recent studies have presented an incongruous proportion of RA concordance in twins. In the study of Svendsen et al. [12], questionnaires were mailed to 37,338 twins from the Danish twin population. Their results indicated that RA prevalence was confirmed clinically in $36 \mathrm{DZ}$ and $13 \mathrm{MZ}$ twins. Unexpectedly, a $0 \% \quad \mathrm{MZ}$ and $8.8 \% \quad \mathrm{DZ}$ concordance was reported [12]. In contrast, the heritability of RA was estimated to be $53 \%$ in the UK cohort study and $65 \%$ in the Finnish study, highlighting the involvement of a wide spectrum of genetic factors in the RA pathogenesis [15]. Other studies that have investigated the heritability rate of different autoantibodies in RA have highlighted the essential role of genetic components in anti-citrullinated antibodies (ACA)-negative RA patients [16].

Similar to many autoimmune disorders, the prevalence of RA is higher in women than in men, and this has also been reported in many twin studies. In the study of Silman et al., $85.7 \%$ of MZ twins [11] versus $82.1 \%$ of the DZ twins were female. Moreover, a concordance of $16.7 \%$ versus a concordance of $3.8 \%$ was demonstrated in female-female $\mathrm{MZ}$ twins compared to female-female DZ twins [11]. This trend of high prevalence among females was also indicated by the study of Svendsen et al. [12], in which the prevalence rates of female $\mathrm{MZ}$ and $\mathrm{DZ}$ twins were $69.2 \%$ and $69.4 \%$, respectively. This inclination in the ratio of male/female twins was also shown by the survey of Van Der Woude et al. [16]. The female dominance of RA is revealed in the relative risk of $4: 3$ in females versus males [14]. The major variable which 
influences the concordance rate of RA among twins is gender. In their study, MacGregor et al. [15] estimated concordance rates between male and female twin pairs in Britain and Finland; a $9.5 \%$ concordance for RA in Finnish male $\mathrm{MZ}$ pairs versus $2.3 \%$ in DZ pairs was shown [15]. Furthermore, the concordance rate for female MZ pairs was $13.5 \%$, while this rate was observed to be $3.8 \%$ between DZ pairs. Additionally, the concordance rate for British male $\mathrm{MZ}$ pairs was $7.7 \%$ in comparison to $0 \%$ in DZ pairs. In contrast to males, the concordance rates for females in $\mathrm{MZ}$ and $\mathrm{DZ}$ twins were $16.7 \%$ and $3.8 \%$, respectively [15]. There was also a $4.5 \%$ oppositesex pair concordance between British twins [15]. Since the emergence of GWAS studies, more than 30 genes have been identified that demonstrate associations with RA risk [17-24]. Among them, KAZALD1, PRKCQ, and TNFAIP2 need further precise investigations, while others such as IL12RB, PTPN22, HLA-DQA1, HLA-DRA1, $H L A-D R B 1$, and $M I C A$ have been strongly associated with RA susceptibility [17, 18]. Chromosome 4q27, which had previously been associated with type 1 diabetes mellitus (T1DM), was identified in association with RA risk, proposing that this locus might confer a shared risk for autoimmune disease development [25]. It has been hypothesized that an unaffected twin might be in an intermediate or temporary condition of immune impairment, which could facilitate the development of RA in cases with sufficient and essential environmental factors [26]. Epigenetic modifications as well as other exposures present extra contributing factors for consideration in the initiation and perpetuation of RA and might shed new light on the exploration of the roles of genetic factors in RA and other autoimmune disorders [27]. The emerging epigenetic mechanisms affect the expression of genes by modifying the histone proteins and methylation of DNA CpGs, which could somehow elucidate the disagreement in concordance rates between twins [28]. The implications of the epigenetic involvement observed in twin pairs will be discussed with more detail in upcoming sections.

\section{Systemic lupus erythematosus}

SLE is a good example of the potential restrictions associated with variable diagnostic criteria or publication bias over the years to explain concordance rates. One broad literature review [29] evaluated 247 twins who had at least one case of SLE. Of these, 60/151 (40\%) MZ twins versus 4/96 (4\%) DZ twins were clinically concordant [29]. Moreover, the study of Block et al. [30] described 12 pairs of female-female twins, including 3 DZ, $7 \mathrm{MZ}$, and 2 of undetermined zygosity, and compared these with 17 previously reported twins. They found that 4 out of $7 \mathrm{MZ}$ twins (57\%) were concordant for SLE, whereas there was a $71 \%$ concordance for hypergammaglobulinemia and the anti-nuclear factor [30]. Interestingly, Block et al. reported in another study the follow-up results of subsequent concordance in twins that were discordant during initial evaluations [29]. This observation emphasizes that the exact and accurate estimation of concordance rates may require a long follow-up period for twin pairs. It has been revealed that unaffected $\mathrm{MZ}$ or DZ twins often have immunological and serological irregularities, including lymphocyte tubuloreticular inclusions (TRIs) and self-reactive antilymphocyte antibodies [31,32]. As is true for other autoimmune diseases, it is possible that epigenetic modifications play a major role in MZ and DZ twin discrepancies and SLE outcomes [33, 34]. A cohort study of $\mathrm{MZ}$ twins and HLA identical siblings in Australia described that none of six DZ, one of four $\mathrm{MZ}$, and none of 18 HLA identical siblings displayed concordance for SLE [35], implying that non-HLA genes play a critical role in the pathogenesis of SLE [35]. Up to now, more than 35 genes have been associated with SLE risk, many of which have been near the threshold of genome-wide association significance [36-49]. Significant associations have been demonstrated in complement genes, FC $\gamma$ receptor genes, and HLA regions [36]. In a GWAS on 1717 SLE patients and 4813 healthy subjects, various genes including ITGAM, STAT4, IRF5, and HLA were discovered to be related with the production of antidsDNA antibody in SLE [38]. Furthermore, the association of TNSF4 and BANK1 with SLE in different populations like Hong Kong, Caucasian, and Chinese have been addressed [39, 50]. The possibility of finding other associations is not far off; however, the study of the importance of gene-gene interaction and its association with the pathogenesis of SLE is still in its infancy [48].

\section{Systemic sclerosis}

While the number of twin studies in SSc is limited, those which have been conducted have demonstrated that there is a poor concordance between $\mathrm{MZ}$ twins for the clinical manifestation of SSc. On the other hand, a significant concordance for molecular and immunological features of SSc was identified through these studies [51-54]. A study of 703 families in the USA, including 11 SSc families, indicated a $0.026 \%$ frequency in the common population compared to a $1.6 \%$ frequency of SSc between firstdegree relatives [55]. In another large twin study of SSc, including 18 DZ twins (1 male, 13 females, and 4 opposite-sex pairs) and $24 \mathrm{MZ}$ (1 male, 23 females) 
twins, the DZ twin concordance was $5.6 \%$ versus $4.2 \%$ between $\mathrm{MZ}$ twins [51]. Furthermore, the concordance rate for anti-nuclear antibody (ANA) was estimated to have a $40 \%$ concordance in DZ twins versus $90 \%$ concordance between $\mathrm{MZ}$ twins [51]. The microarray study of Zhou et al. including 5 DZ discordant, $10 \mathrm{MZ}$ pairs, and 5 healthy subjects also presented a good concordance for molecular mechanisms of SSc in MZ twins [52]. Moreover, the fibroblast gene expression profiles of SSc patients between non-concordant DZ twins and healthy subjects were inconsistent. However, the fibroblast gene expression profile of MZ twins was similar among SSc patients [52]. The upregulation of CTGF, COL1A2, and SPARC, which are SSc signature genes, was observed in a healthy pair of MZ twins [52]. Taken together, while the concordance rate between MZ twins is low, the molecular features of SSc showed a significant concordance, which may not be manifested through the clinical picture of SSc. These findings are supportive of a high genetic susceptibility in the pathogenesis of SSc.

The genetic implications of SSc have also been elucidated in a recent GWAS [56-60]. Prior studies had reported the association of SSc with CD247, STAT4, BANK1, IRF5, BLK, and TNFSF4 [56-69], whereas another GWAS showed different results [70]. In the later study which included four cohorts of 5171 healthy individuals and 2296 SSc patients [70], the polymorphisms of IRF8 were associated with limited cutaneous SSc (lcSSc), while ACA-positive $1 \mathrm{cSSc}$ was related to the SOX5 and GRB10 genes [70]. There was an association between ACA positivity and HLA-DQB1, while the anti-topoisomerase I antibody (ATA) was related to HLA-DPA1/B1 [70]. ATA positivity together with ACA revealed an association with the $\mathrm{NOTCH} 4$ gene [70].

\section{Ankylosing Spondylitis}

Genetic studies of AS have provided a deep understanding of the etiopathogenesis of the disease. It has been established that AS predisposition and the intensity of clinical complications are determined mainly through genetic components. Vast advances in exploring the susceptibility alleles in AS have discovered 113 loci with the direct implication that they are responsible for approximately $10 \%$ of AS heritability. However, it has been established that the human leukocyte antigen (HLA)-B27 affects roughly $10 \%$ of the AS genetic risk. Investigations of familial AS cases have demonstrated that $20 \%$ of first-degree relatives with AS probands develop the disease [71-79]. Other than genetics, a few epigenetic studies have also shed new light on the disease etiology and pathogenesis [80].

Although extensive research has revealed a major role of genetic risk factors in the AS etiopathogenesis, fewer twin pair evaluations have addressed this issue. In a cohort study that evaluated 26 pairs of Finnish twins (6 $\mathrm{MZ}$ pairs and $20 \mathrm{DZ}$ pairs), it was observed that both individuals in $3 \mathrm{MZ}$ pairs and $3 \mathrm{DZ}$ pairs were affected by AS. Also, $2 \mathrm{MZ}$ pairs were completely discordant for AS characteristics. All the affected cases were HLA-B27 positive. On the contrary, all 5 unaffected DZ twins were B27 negative. This investigation demonstrated that the development of AS lays largely on genetic components, HLA-B27 may play a role in this susceptibility [78]. An evaluation of AS twins from the Royal National Hospital for Rheumatic Diseases database demonstrated that genetics determines a major part of AS susceptibility. Moreover, environmental factors may also contribute to disease proneness, as HLA-B27 was observed to play a minor role in overall AS genetic susceptibility. Other than HLA-B27, HLA-B60 was also associated with AS in probands. Additionally, in the study of Brown et al., 6 out of $8 \mathrm{MZ}$ twins, 4 out of 15 B27-positive DZ twins, and 4 out of all 32 DZ twins were concordant for AS [81]. A Norwegian and two Danish nationwide twin surveys comprising 37,388 and 46,331 Danish twin individuals were determined by questionnaire if they were affected with AS in 1994 and 2002, respectively. After validation, it was observed that 39 probands had AS. This survey disclosed that MZ twins were $40 \%$ concordant for AS, while DZ twin pairs were $4 \%$ concordant. Although selfreporting AS by questionnaire needs careful confirmation, AS prevalence in a Danish twin population was $0.1 \%$. This cohort twin study assigned, again, a role to genetic factors in AS etiopathogenesis [82]. Although these investigations are few in number, they do demonstrate the strong role of genetics in AS susceptibility.

\section{Psoriasis}

Psoriatic disorders are systemic inflammatory settings, which comprise psoriasis and psoriatic arthritis (PsA) and affect both genders similarly [83]. Ranging from $20 \%$ to $64 \%, \mathrm{MZ}$ twins display high concordance rates in patients with skin psoriasis and a higher incidence in male pairs [84-88]. Epidemiological studies have demonstrated that genetic risk factors are responsible for $68 \%(60-75 \%)$ of the psoriasis susceptibility, while the remaining variation is justified through environmental factors and epigenetic modifications [84, 89]. Evidence has proven that psoriasis and PsA are of different genetic backgrounds, as observed by the association between different phenotypes of 
psoriasis and HLA-Cw06 or HLA-B27 [90]. Psoriatic cases have rarely been studied in twins; thus, further investigations are required to achieve a clear picture of the role of genetics in psoriasis proneness.

\section{Epigenetics implications}

Today, the contributions of both genetic factors and environmental elements to the development of autoimmune diseases have been established. Studies have proven that there is an unaffected twin in most cases of MZ or DZ twins with an autoimmune disorder. While the investigation of concordant twins has recognized genetic risk factors, the concordance rates in most autoimmune disorders are remarkably low, implying to the involvement of other regulatory mechanisms in determining the disease onset and development. While phenotypic concordant twin cases for autoimmune disorders can be employed to investigate the heritability and genetic implications, discordant cases allow the evaluation of the role of non-genetic factors. On the other hand, numerous initially unaffected twins have been observed through follow-up studies to develop the disease in the future. Despite the favorable potential of MZ twins to be exerted in the evaluation of epigenetic implications in the development of autoimmune disorders, little has been investigated within this context. The dysregulation of epigenetic marks has been extensively studied in autoimmune disorders. Of note, aberrancies in the DNA methylation pattern in $\mathrm{CpG}$ islands have concentrated mainly on RA, SLE, and SSc. Early abnormal alterations in DNA methylation patterns were noticed in T cells from patients with autoimmune diseases like SLE and RA, supporting a global hypomethylation of DNA [27].

\section{Environmental triggers and autoimmune diseases}

Environmental risk factors that are intensely associated with the development of autoimmune disorders are smoking, low serum levels of vitamin D, and infectious agents [91]. Smoking has been reported to affect epigenetic marks such as DNA methylation [92, 93], histone acetylation [94], and the expression profile of miRNAs [93]. Vitamin D has been reported to have an active role in the status of histone modifications such as recruiting histone acetyltransferases or histone deacetylases to the vitamin D target genes, hence regulating the expression circumstances of the related genes [95]. Moreover, the Epstein-Barr virus (EBV) actively employs the epigenetic mechanisms of its host and modulates the expression of viral genes in order to survive within host cells [96-98]. Animal studies have established that various environmental factors, including different physical, chemical, and biological agents, are able to either stimulate the onset of an autoimmune disorder or aggravate disease conditions [99]. Environmental factors are able to break immune tolerance by regulating the posttranslational modifications thereby triggering a span of immune responses $[100,101]$.

\section{Epigenetic regulatory mechanisms}

Epigenetics is commonly characterized as heritable modifications in a gene expression pattern without an alteration in the DNA sequence. During the normal physiology and biology of the cells, epigenetics explains how cells differentiate into diverse types, while they contain a limited number of genes [102]. Epigenetic regulatory mechanisms are evaluated in three levels: first, those that occur in DNA molecules, specifically methylation of the $5^{\text {th }}$ carbon in the cytosine of $\mathrm{CpG}$ dinucleotides that causes suppression of gene expression; second, the biochemical alterations in histone proteins, in which the well-studied modification of histone acetylation culminates in the activation of gene transcription (Fig. 1); and third, mRNA regulation through microRNAs, which are small non-coding RNA molecules.

\section{Rheumatoid arthritis}

The biostatistical approach, optimized for a small sample size in RA twin studies, discovered aberrant DNA methylation patterns in cases with different autoantibody profiles. It was observed that seven twins discordant for antibodies to citrullinated protein antigens (ACPA)positive RA disclosed significant differently methylated regions. Further analysis resulted in the identification of the EXOSC1 gene with a strong, significantly different methylation profile between twins [103]. The EXOSC1 gene encodes a core component of the exosome, which is vitally involved in innate immunity. Alternately, several members of the exosome family have been observed to be the targets of autoantibodies in autoimmune disorders [104].

An epigenome-wide association study of $28 \mathrm{MZ}$ twin pairs discordant for RA revealed that there were several differentially methylated regions associated with RA. Smoking, as an environmental factor, demonstrated an association with promoter region hypomethylation in the RNF5 and AGPATl genes, both of which are involved in autoinflammatory conditions. Moreover, diseasemodifying antirheumatic drug (DMARD) treatment was observed to play a role in triggering the hypermethylation of these genes. These observations provide an understanding that environmental factors are involved in RA pathogenesis by affecting the epigenome content of the regions involved in pathobiological pathways. 
Twin studies in autoimmunity

Moreover, the S100A6 and EFCAB4B genes were hypomethylated in the promoter regions. Further gene-set analyses of the results from epigenome-wide data demonstrated the involvement of immunologic signatures in RA pathogenesis [105].

\section{Systemic lupus erythematosus}

Evaluation of DNA methylation circumstances in the promoter of genes has led to the identification of perforin DNA demethylation in SLE CD4+ $T$ cells [106], associated with intensified killing of monocytes in such patients. The upregulation of the CD70 gene, which results in B cell over-stimulation, was associated with its promoter demethylation in SLE CD4+ T cells [107]. Furthermore, the same events have been observed in the promoter of the ITGAL (CDIla) gene, contributing to the development of SLE [107].

The dysregulation of DNA methylation and gene expression have been elucidated in 10 genes in discordant SLE MZ twins [108]. On the other hand, a cohort study of MZ twins discordant for three autoimmune diseases with shared clinical signs, including SLE, RA, and dermatomyositis, has strengthened the understanding of the functions of epigenetics alterations in autoimmune diseases. In this study, discordant SLE MZ twins demonstrated DNA hypomethylation in numerous genes, mostly related to the immune function as identified through gene ontology analysis. Further evaluations led to the recognition of alterations in both methylation and expression of the loci associated with SLE pathogenesis. It appears that DNA methylation abnormalities play roles in the SLE pathogenesis and may determine its clinical picture; furthermore, they are involved in distinguishing the autoimmune diseases by impressing the clinical manifestations [33].
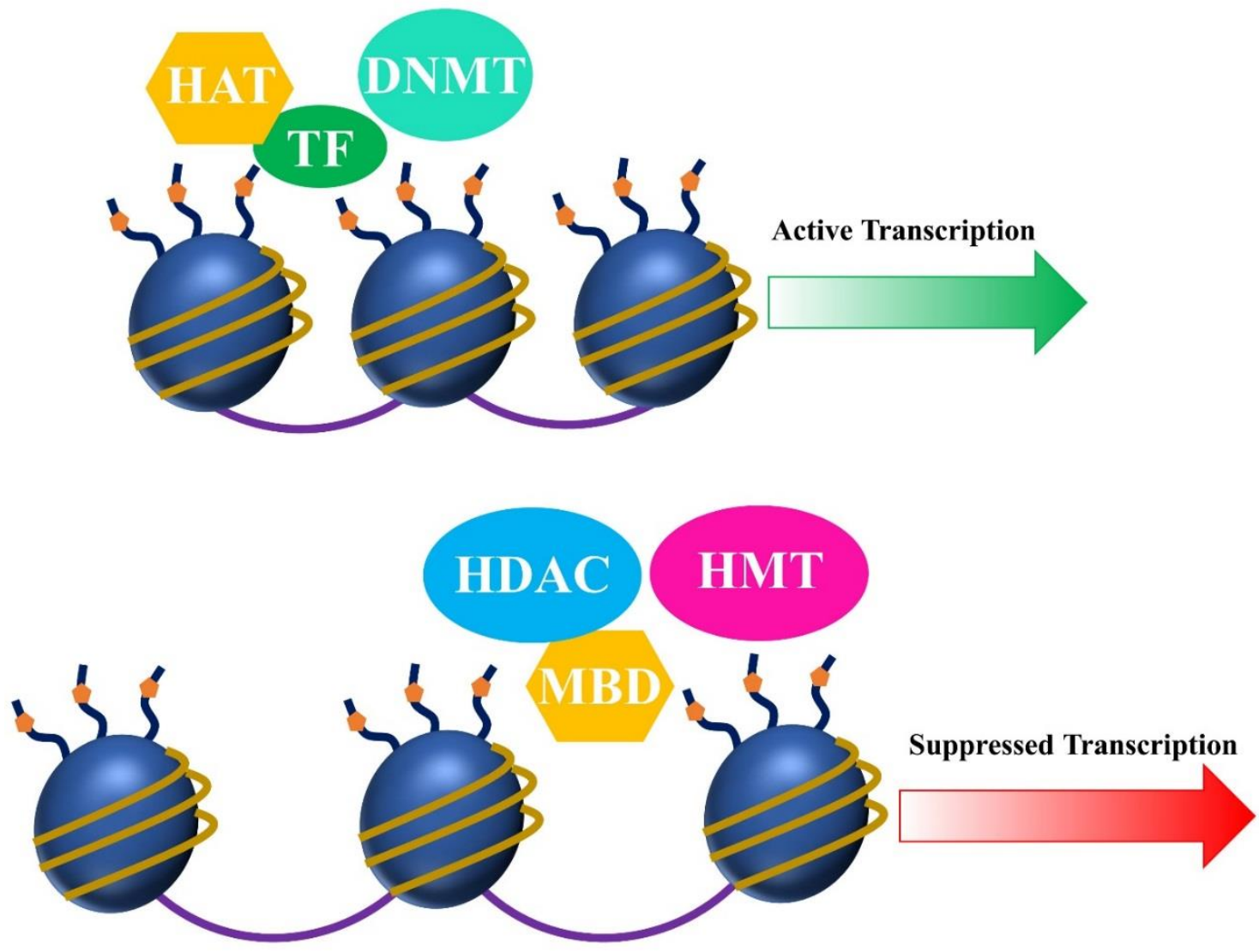

Fig. 1. Various nuclear factors collaborate to establish an epigenetically active (upper) or silenced (lower) configuration. DNA methyltransferases (DNMT) and histone acetyltransferase (HAT), by adding methyl groups to the CpG sites located in the promoter of gene and acetylation of histone tails, cause the suppression of gene expression (heterochromatin conformation). Methyl-CpG-binding domain (MBD) proteins are associated with methylated DNA and recruited by histone deacetylases (HDAC) and histone methyltransferases (HMT) enzymes in order to suppress the transcription of genes (euchromatin conformation). 


\section{Systemic sclerosis}

Even though discordant $\mathrm{MZ}$ twins are potentially favorable prospects for studying the SSc pathogenesis epigenetically, there has been only one investigation in this regard to date. A comparison of methylation profiles was carried out on genes located in the $\mathrm{X}$ chromosome in peripheral blood mononuclear cells (PBMCs) from 7 discordant $\mathrm{MZ}$ twins and 1 concordant $\mathrm{MZ}$ twin for SSc. Differently methylated regions were investigated through biostatistical methods and resulted in the identification of 18 hypermethylated and 25 hypomethylated regions in affected twins. Enrichment analyses demonstrated the involvement of these genes in pathways like apoptosis (MTM1), cell proliferation (SSR4, PGK1, SMS, and UTP14A), oxidative stress (ENOX2), and inflammation $(A R A F)$. Among the differently methylated genes were PGRMC1 and IL1RAPL2 as well as genes encoding transcription factors such as $H S F X 1, Z B E D 1, Z N F 41$, and $A R X$. The results indicated that the methylation dysregulation of the $\mathrm{X}$ chromosome genes is probably involved in SSc pathogenesis [109].

\section{Ankylosing spondylitis}

Generally, a few surveys have inspected AS etiopathogenesis under the light of epigenetic aberrations. These studies focused on DNA methylation [110, 111], histone modifications [112], and microRNAs [113-116]. Nonetheless, no study has evaluated the role of epigenetic dysregulation in susceptibility to AS applying twin pairs. As most autoimmune disorders have been evaluated with regard to the disease causality seen in twin cases, a gap exists for AS. Hopefully, the application of such valuable study models in AS will open up new horizons for the study of AS etiopathogenesis.

The application of high-throughput approaches and epigenome-wide studies as well as the evaluation of suitable animal models can provide further understanding of the involvement of epigenetic dysregulations in autoimmune pathogenesis. Discordant MZ twins with virtually identical genetic content can be appropriate tools to exclusively investigate the epigenetic marks, as they decline the chance of interfering elements of genetic heterogeneity like single nucleotide polymorphisms (SNPs).

\section{Psoriasis}

The role of environmental factors in the etiopathogenesis of psoriasis is supported by the evidence that shows different onset ages in concordant MZ twins, because early-onset psoriasis is not predominantly genetically determined [117].

Genome-wide evaluations in DNA methylation status and gene expression profiles in CD4+ and CD8+ cells demonstrated no differentially expressed or methylated genes between twins with psoriasis. However, a substantial number of small differences was observed in the players of the immune response, such as cytokines and chemokines [118]. Smoking is an important environmental factor that is assumed to influence the development of psoriatic diseases. Moreover, it has recently been reported that exposure to environmental smoke during childhood is significantly related with the development of psoriasis [119].

A limited number of twin studies performed in PsA patients indicated identical concordance rates for PsA in $\mathrm{MZ}$ and DZ twins, suggesting the substantial role of nongenetic players in PsA etiopathogenesis [120]. A deep Koebner phenomenon or repeated joint trauma may accelerate the development of PsA, as was seen in a case report of MZ twins who developed PsA following a trauma [121]. Furthermore, the skin microbiome has been suggested to be a central player in the development of PsA; however, the profiling of the bacterial culture in the psoriatic plaques did not differences at the phylum and genus levels between individuals [122].

Table 1. Summary of epigenetic dysregulation findings in autoimmune twin cases

\begin{tabular}{|c|c|c|c|}
\hline Disease & Twin type & Modification & Reference \\
\hline \multirow[b]{2}{*}{ RA } & 7 twins discordant for RA & Different methylation of EXOSCl Gene & [103] \\
\hline & $28 \mathrm{MZ}$ twin pairs discordant for RA & $\begin{array}{l}\text { hypomethylation of } R N F 5, A G P A T 1, \text { S100A6 and } \\
\qquad E F C A B 4 B\end{array}$ & [105] \\
\hline SLE & Discordant SLE MZ twins & $\begin{array}{l}\text { DNA hypomethylation in several genes, mostly related to } \\
\text { immune function }\end{array}$ & [33] \\
\hline SSc & $\begin{array}{l}7 \text { discordant } \mathrm{MZ} \text { twins and } 1 \text { concordant } \mathrm{MZ} \\
\text { twin }\end{array}$ & $\begin{array}{l}18 \text { hypermethylated and } 25 \text { hypomethylated regions; } \\
\text { PGRMC1, IL1RAPL2, HSFX1, ZBED1, ZNF41, and } \\
\text { ARX }\end{array}$ & [109] \\
\hline Psoriasis & Psoriasis twins & $\begin{array}{l}\text { NO differentially expressed or methylated genes in CD4+ } \\
\text { and CD8+ cells between twins with psoriasis }\end{array}$ & [118] \\
\hline
\end{tabular}




\section{Conclusion}

Little is known about the etiopathogenesis of autoimmune disease. Nevertheless, it seems that the close nexus between contributing environmental factors and genetic elements is of great importance in the loss of immunological tolerance. Studies of twins with autoimmune disorders have provided a great deal of data regarding the genetics, epigenetics, and environmental factors related to disease initiation, pathogenesis, and perpetuation. The paucity of twin studies in several autoimmune diseases stems from various conditions, particularly and most challengingly, the infrequency of cases. Other than genetic factors, epigenetic factors and rare variants must be further studied using cases with shared geo-environments, which might be promising in furthering the knowledge of the etiopathogenesis of autoimmune conditions. Furthermore, the utilization of cutting-edge techniques for evaluating the whole genome and epigenome methylation patterns may shed further light on autoimmune diseases, as such studies have rarely been conducted. Gender-associated factors should also be taken into consideration as a female predominance has been highlighted in concordant twins of autoimmune disorders. Hopefully, twin studies will open up new horizons in the acknowledgment and illumination of genetic, epigenetic, and environmental factors engaged in the pathogenesis of autoimmune complications.

\section{Conflicts of interest}

The authors declare no conflict of interest.

\section{Acknowledgments}

This study was supported by a grant from the Deputy of Research, Tehran University of Medical Sciences (Grant No. 94-02-41-29598).

\section{References}

1. Lykken DT, Tellegen A, DeRubeis R. Volunteer bias in twin research: The rule of two-thirds. Social Biology 1978; 25(1): 1-9, doi: 10.1080/19485565.1978.9988312.

2. Phillips DI. Twin studies in medical research: can they tell us whether diseases are genetically determined? The Lancet 1993; 341(8851): 100809, doi: 10.1016/0140-6736(93) 91086-2.

3. Juran BD, Lazaridis KN. Genomics and complex liver disease: Challenges and opportunities. Hepatology 2006; 44(6): 1380-90, doi: 10.1002/hep.21453.

4. Bogdanos DP, Smyk DS, Rigopoulou EI, Mytilinaiou MG, Heneghan MA, Selmi C. et al. Twin studies in autoimmune disease: genetics, gender and environment. Journal of Autoimmunity 2012; 38(2): J156-J69, doi: 10.1016/j.jaut. 2011.11.003.

5. Salvetti M, Ristori G, Bomprezzi R, Pozzilli P, Leslie RDG. Twins: mirrors of the immune system. Immunology Today 2000; 21(7): 342-47, doi:10.1016/s0167-5699 (00)01658-3.

6. Kaminsky ZA, Tang T, Wang SC, Ptak C, Oh GH, Wong AH. et al. DNA methylation profiles in monozygotic and dizygotic twins. Nature genetics 2009; 41(2): 24045, doi: 10.1038/ng.286.

7. Greco L, Romino R, Coto I, Di Cosmo N, Percopo S, Maglio M. et al. The first large population based twin study of coeliac disease. Gut 2002; 50(5): 624-28, doi: 10.1136/ gut.50.5.624.

8. Hervonen K, Karell K, Holopainen P, Collin P, Partanen J, Reunala T. Concordance of dermatitis herpetiformis and celiac disease in monozygous twins. Journal of Investigative Dermatology 2000; 115(6): 990-93, doi: 10.1046/j.15231747.2000.00172.x.

9. Aho K, Koskenvuo M, Tuominen J, Kaprio J. Occurrence of rheumatoid arthritis in a nationwide series of twins. The Journal of rheumatology 1986; 13(5): 899-902.

10. Järvinen $P$, Aho K: Twin studies in rheumatic diseases. In: Seminars in arthritis and rheumatism: 1994: Elsevier; 1994; 24(1): 19-28, doi: 10.1016/0049-0172(94)90096-5.

11. Silman A, MacGregor A, Thomson W, Holligan S, Carthy D, Farhan A. et al. Twin concordance rates for rheumatoid arthritis: results from a nationwide study. Rheumatology 1993; 32(10): 903-07, doi: 10.1093/rheumatology/32.10.903.

12. Svendsen AJ, Silman AJ, Holm NV, Kyvik K, Petersen PH, Junker P. Relative importance of genetic effects in rheumatoid arthritis: historical cohort study of Danish nationwide twin population Commentary: Do genes or environment influence development of rheumatoid arthritis? Bmj 2002;
324(7332): 264, doi: 10.1136/bmj. 324.7332 .264

13. JS L, Oration H. Rheumatoid arthritis--nature or nurture? Annals of the Rheumatic Diseases 1970; 29(4): 357-79, doi: 10.1136/ard.29. 4.357.

14. Bellamy N, Duffy D, Martin N, Mathews J. Rheumatoid arthritis in twins: a study of aetiopathogenesis based on the Australian Twin Registry. Annals of the Rheumatic Diseases 1992; 51(5): 588-93, doi: 10.1136/ard.51.5.588.

15. MacGregor AJ, Snieder H, Rigby AS, Koskenvuo M, Kaprio J, Aho $\mathrm{K}$. et al. Characterizing the quantitative genetic contribution to rheumatoid arthritis using data from twins. Arthritis \& Rheumatology 2000; 43(1): 30-37, doi: 10.1002/1529-0131(200001)43:1< 30::aid-anr5>3.0.co;2-b.

16. van der Woude D, HouwingDuistermaat JJ, Toes RE, Huizinga TW, Thomson W, Worthington J. et al. Quantitative heritability of anticitrullinated protein antibodypositive and anti-citrullinated protein antibody-negative rheumatoid arthritis. Arthritis \& Rheumatology 2009; 60(4): 916-23, doi: 10.1002/art.24385.

17. Consortium WTCC. Genome-wide association study of 14,000 cases of seven common diseases and 3,000 shared controls. Nature 2007; 447(7145): 661

Rheum. Res., Vol. 3, No. 2, Apr. 2018 
18. Eleftherohorinou $\mathrm{H}$, Hoggart CJ, Wright VJ, Levin M, Coin LJ. Pathway-driven gene stability selection of two rheumatoid arthritis GWAS identifies and validates new susceptibility genes in receptor mediated signalling pathways. Human Molecular Genetics 2011; 20(17): 3494-506, doi: 10.1093/ hmg/ddr248.

19. Imboden JB. The immunopathogenesis of rheumatoid arthritis. Annual Review of Pathological Mechanical Disease 2009; 4(1): 417-34, doi: 10.1146/ annurev.pathol.4.110807.092254.

20. Plenge RM, Cotsapas C, Davies L, Price AL, De Bakker PI, Maller J. et $a l$. Two independent alleles at 6q23 associated with risk of rheumatoid arthritis. Nature Genetics 2007; 39(12): 1477-82, doi: 10.1038/ng. 2007.27.

21. Plenge RM, Seielstad M, Padyukov L, Lee AT, Remmers EF, Ding B. et al. TRAF1-C5 as a risk locus for rheumatoid arthritis - a genomewide study. New England Journal of Medicine 2007; 357(12): 1199-209, doi: 10.1056/nejmoa073491.

22. Raychaudhuri S, Remmers EF, Lee AT, Hackett R, Guiducci C, Burtt NP. et al. Common variants at CD40 and other loci confer risk of rheumatoid arthritis. Nature Genetics 2008; 40(10): 1216-23, doi: 10.1038/ng.233.

23. Remmers EF, Plenge RM, Lee AT, Graham RR, Hom G, Behrens TW. et al. STAT4 and the risk of rheumatoid arthritis and systemic lupus erythematosus. New England Journal of Medicine 2007; 357(10): 977-86, doi:10.1056/nejmoa073003.

24. Stahl EA, Raychaudhuri S, Remmers EF, Xie G, Eyre S, Thomson BP. et al. Genome-wide association study meta-analysis identifies seven new rheumatoid arthritis risk loci. Nature Genetics 2010; 42(6): 508-14.

25. Zhernakova A, Alizadeh BZ, Bevova M, van Leeuwen MA, Coenen MJ, Franke B. et al. Novel association in chromosome $4 \mathrm{q} 27$ region with rheumatoid arthritis and confirmation of type 1 diabetes point to a general risk locus for autoimmune diseases. The American Journal of Human Genetics 2007; 81(6): 1284-88, doi: $10.1086 / 522037$.

26. O'Hanlon TP, Rider LG, Gan L,
Fannin R, Paules RS, Umbach DM. et al. Gene expression profiles from discordant monozygotic twins suggest that molecular pathways are shared among multiple systemic autoimmune diseases. Arthritis Research \& Therapy 2011; 13(2): R69, doi: 10.1186/ar3330.

27. Aslani S, Mahmoudi M, Karami J, Jamshidi AR, Malekshahi Z, Nicknam MH. Epigenetic alterations underlying autoimmune diseases. Autoimmunity 2016; 49(2): 69-83, doi: $\quad 10.3109 / 08916934.2015$. 1134511.

28. Ballestar E. Epigenetic alterations in autoimmune rheumatic diseases. Nature Reviews Rheumatology 2011; 7(5): 263-71, doi: 10.1038/ nrrheum.2011.16.

29. Block S: A brief history of twins. In.: Sage Publications Sage CA: Thousand Oaks, CA; 2006.

30. Block S, Winfield J, Lockshin M, d'Angelo W, Christian C. Studies of twins with systemic lupus erythematosus: a review of the literature and presentation of 12 additional sets. The American Journal of Medicine 1975; 59(4): 533-52, doi: 10.1016/0002-9343(75) 90277-6.

31. Block SR, Lockshin MD, Winfield JB, Weksler ME, Imamura $M$, Winchester RJ. et al. Immunologic observations on 9 sets of twins either concordant or discordant for SLE. Arthritis \& Rheumatology 1976; 19(3): 545-54, doi: 10.1002/ art. 1780190306

32. Reichlin M, Harley JB, Lockshin MD. Serologic studies of monozygotic twins with systemic lupus erythematosus. Arthritis \& Rheumatology 1992; 35(4): 457-64, doi: 10.1002/art.1780350416.

33. Javierre BM, Fernandez AF, Richter J, Al-Shahrour F, Martin-Subero JI, Rodriguez-Ubreva J. et al. Changes in the pattern of DNA methylation associate with twin discordance in systemic lupus erythematosus. Genome Rsearch 2010; 20(2): 17079, doi: $10.1101 /$ gr.100289.109.

34. Patel DR, Richardson BC. Epigenetic mechanisms in lupus. Current Opinion in Rheumatology 2010; 22(5): 478-82, doi: 10.1097/ bor.0b013e32833ae915.

35. Grennan D, Parfitt A, Manolios N, Huang Q, Hyland V, Dunckley H. et al. Family and twin studies in systemic lupus erythematosus.
Disease Markers 1997; 13(2): $93-$ 98.

36. Sestak AL, Fürnrohr BG, Harley JB, Merrill JT, Namjou B. The genetics of systemic lupus erythematosus and implications for targeted therapy. Annals of the Rheumatic Diseases 2011; 70(Suppl 1): i37-i43, doi: 10.1136/ard.2010.138057.

37. Consortium IMSG. Refining genetic associations in multiple sclerosis. Lancet neurology 2008; 7(7): 56769, doi: 10.1016/s1474-4422(08) 70122-4.

38. Chung SA, Taylor KE, Graham RR, Nititham J, Lee AT, Ortmann WA. et al. Differential genetic associations for systemic lupus erythematosus based on AntidsDNA autoantibody production. PLoS Genetics 2011; 7(3): e1001323, doi: 10.1371/journal. pgen.1001323.

39. Graham DSC, Graham RR, Manku $\mathrm{H}$, Wong AK, Whittaker JC, Gaffney PM. et al. Polymorphism at the TNF superfamily gene TNFSF4 confers susceptibility to systemic lupus erythematosus. Nature Genetics 2008; 40(1): 83-89, doi: 10.1038/ng.2007.47.

40. Graham RR, Cotsapas C, Davies L, Hackett R, Lessard CJ, Leon JM. et al. Genetic variants near TNFAIP3 on $6 \mathrm{q} 23$ are associated with systemic lupus erythematosus. Nature Genetics 2008; 40(9): 105961, doi: 10.1038/ng.200.

41. Hom G, Graham RR, Modrek B, Taylor KE, Ortmann W, Garnier S. et al. Association of systemic lupus erythematosus with C8orf13-BLK and ITGAM-ITGAX. New England Journal of Medicine 2008; 358(9): 900-09, doi: 10.1056/nejmoa 0707865.

42. Ioannidis JP. Non-replication and inconsistency in the genome-wide association setting. Human Heredity 2007; 64(4): 203-13, doi: 10.1159/000103512.

43. Kozyrev SV, Abelson A-K, Wojcik J, Zaghlool A, Reddy MPL, Sanchez E. et al. Functional variants in the B-cell gene BANK1 are associated with systemic lupus erythematosus. Nature Genetics 2008; 40(2): 21116, doi: 10.1038/ng.79.

44. Li M, Li C, Guan W. Evaluation of coverage variation of SNP chips for genome-wide association studies. European Journal of Human Genetics: EJHG 2008; 16(5): 635-

Rheum. Res., Vol. 3, No. 2, Apr. 2018 
Twin studies in autoimmunity

43, doi: 10.1038/sj.ejhg.5202007.

45. Neale BM, Purcell S. The positives, protocols, and perils of genomewide association. American Journal of Medical Genetics Part B: Neuropsychiatric Genetics 2008; 147(7): 1288-94, doi: 10.1002/ajmg. b. 30747 .

46. Price AL, Patterson NJ, Plenge RM, Weinblatt ME, Shadick NA, Reich D. Principal components analysis corrects for stratification in genomewide association studies. Nature Genetics 2006; 38(8): 904-09, doi: 10.1038/ng1847.

47. Suarez-Gestal M, Calaza M, Endreffy E, Pullmann R, Ordi-Ros J, Sebastiani GD. et al. Replication of recently identified systemic lupus erythematosus genetic associations: a case-control study. Arthritis Research \& Therapy 2009; 11(3): R69, doi: 10.1186/ar2698.

48. Zhou $\mathrm{Xj}$, Lu Xl, Nath SK, Lv Jc, Zhu Sn, Yang Hz. et al. Gene-gene interaction of BLK, TNFSF4, TRAF1, TNFAIP3, and REL in systemic lupus erythematosus. Arthritis \& Rheumatology 2012; 64(1): 222-31, doi: 10.1002/art. 33318.

49. Vyse T, Fortin P, Montpetit A, Cai Y, Lim S, McKenzie T. et al. Association of LY9 in UK and Canadian SLE families. Genes and Immunity 2008; 9(2): 93-102, doi: 10.1038/sj.gene.6364453.

50. Chang Y, Yang W, Zhao M, Mok C, Chan T, Wong R. et al. Association of BANK1 and TNFSF4 with systemic lupus erythematosus in Hong Kong Chinese. Genes and Immunity 2009; 10(5): 414-20, doi: 10.1038/gene.2009.16.

51. Feghali-Bostwick C, Medsger TA, Wright TM. Analysis of systemic sclerosis in twins reveals low concordance for disease and high concordance for the presence of antinuclear antibodies. Arthritis \& Rheumatology 2003; 48(7): 195663, doi: 10.1002/art.11173.

52. Zhou X, Tan FK, Xiong M, Arnett FC, Feghali-Bostwick CA. Monozygotic twins clinically discordant for scleroderma show concordance for fibroblast gene expression profiles. Arthritis \& Rheumatology 2005; 52(10): 330514, doi: 10.1002/art.21355.

53. Kuwana M, Feghali CA, Medsger TA, Wright TM. Autoreactive T cells to topoisomerase $\mathrm{I}$ in monozygotic twins discordant for systemic sclerosis. Arthritis \& Rheumatology 2001; 44(7): 165459, doi: 10.1002/1529-0131 (200107)44:7<1654::aid-art288> 3.0.co;2-o.

54. Mchugh NJ, Harvey GR, Whyte J, Dorsey JK. Segregation of autoantibodies with disease in monozygotic twin pairs discordant for systemic sclerosis. Arthritis \& Rheumatology 1995; 38(12): 184550, doi: 10.1002/art.1780381219.

55. Arnett FC, Cho M, Chatterjee S, Aguilar MB, Reveille JD, Mayes MD. Familial occurrence frequencies and relative risks for systemic sclerosis (scleroderma) in three United States cohorts. Arthritis \& Rheumatology 2001; 44(6): 1359-62, doi: 10.1002/15290131(200106)44:6<1359::aid-art 228>3.0.co;2-s.

56. Arnett FC, Gourh P, Shete S, Ahn $\mathrm{CW}$, Honey R, Agarwal SK. et al. Major Histocompatibility Complex (MHC) class II alleles, haplotypes, and epitopes which confer susceptibility or protection in the fibrosing autoimmune disease systemic sclerosis: analyses in 1300 Caucasian, African-American and Hispanic cases and 1000 controls. Annals of the Rheumatic Diseases 2009; 69(5): 822-27, doi:10.1136/ard.2009.111906.

57. Bossini-Castillo L, Broen JC, Simeon CP, Beretta L, Vonk MC, Ortego-Centeno N. et al. A replication study confirms the association of TNFSF4 (OX40L) polymorphisms with systemic sclerosis in a large European cohort. Journal of Translational Medicine 2010; 8(1): P5, doi: 10.1186/14795876-8-s1-p5.

58. Dieude P, Guedj M, Wipff J, Avouac J, Fajardy I, Diot E. et al. Association between the IRF5 rs2004640 functional polymorphism and systemic sclerosis: a new perspective for pulmonary fibrosis. Arthritis \& Rheumatology 2009; 60(1): 225-33, doi: 10.1002/art. 24183.

59. Ito I, Kawaguchi Y, Kawasaki A, Hasegawa M, Ohashi J, Hikami K. et al. Association of a functional polymorphism in the IRF5 region with systemic sclerosis in a Japanese population. Arthritis \& Rheumatology 2009; 60(6): 184550, doi: 10.1002/art.24600.
60. Zhou X, Lee JE, Arnett FC, Xiong M, Park MY, Yoo YK. et al. HLADPB1 and DPB2 are genetic loci for systemic sclerosis: A genome-wide association study in Koreans with replication in North Americans. Arthritis \& Rheumatology 2009; 60(12): 3807-14, doi: 10.1002/art. 24982.

61. Dieude P, Guedj M, Wipff J, Ruiz B, Hachulla E, Diot E. et al. STAT4 is a genetic risk factor for systemic sclerosis having additive effects with IRF5 on disease susceptibility and related pulmonary fibrosis. Arthritis \& Rheumatology 2009; 60(8): 2472-79, doi: 10.1002/ art.24688.

62. Dieude P, Wipff J, Guedj M, Ruiz B, Melchers I, Hachulla E. et al. BANK1 is a genetic risk factor for diffuse cutaneous systemic sclerosis and has additive effects with IRF5 and STAT4. Arthritis \& Rheumatology 2009; 60(11): 344754, doi: 10.1002/art.24885.

63. Gourh P, Agarwal SK, Martin E, Divecha D, Rueda B, Bunting H. et al. Association of the C8orf13-BLK region with systemic sclerosis in North-American and European populations. Journal of autoimmunity 2010; 34(2): 155-62, doi: 10.1016/j.jaut.2009.08.014.

64. Gourh P, Arnett FC, Tan FK, Assassi S, Divecha D, Paz G. et al. Association of TNFSF4 (OX40L) polymorphisms with susceptibility to systemic sclerosis. Annals of the rheumatic diseases 2010; 69(3): 550-55, doi: 10.1136/ard.2009. 116434 .

65. Ito I, Kawaguchi Y, Kawasaki A, Hasegawa M, Ohashi J, Kawamoto M. et al. Association of the FAM167A-BLK region with systemic sclerosis. Arthritis \& Rheumatology 2010; 62(3): 890-95, doi: 10.1002/art.27303.

66. Radstake TR, Gorlova O, Rueda B, Martin J-E, Alizadeh BZ, PalominoMorales R. et al. Genome-wide association study of systemic sclerosis identifies CD247 as a new susceptibility locus. Nature Genetics 2010; 42(5): 426-29.

67. Rueda B, Broen J, Simeon C, Hesselstrand R, Diaz B, Suarez H. et $a l$. The STAT4 gene influences the genetic predisposition to systemic sclerosis phenotype. Human Molecular Genetics 2009; 18(11): 2071-77, doi:10.1093/hmg/ddp119. 
68. Rueda B, Gourh P, Broen J, Agarwal S, Simeón C, OrtegoCenteno N. et al. BANK1 functional variants are associated with susceptibility to diffuse systemic sclerosis in Caucasians. Annals of the Rheumatic Diseases 2009; 69(64): 700-05, doi:10.1136/ard. 2009.118174.

69. Tsuchiya N, Kawasaki A, Hasegawa M, Fujimoto M, Takehara K, Kawaguchi Y. et al. Association of STAT4 polymorphism with systemic sclerosis in a Japanese population. Annals of the Rheumatic Diseases 2009; 68(8): 1375-76, doi: 10.1136/ard.2009. 111310.

70. Gorlova O, Martin JE, Rueda B, Koeleman BP, Ying J, Teruel M. et al. Identification of novel genetic markers associated with clinical phenotypes of systemic sclerosis through a genome-wide association strategy. PLoS Genetics 2011; 7(7): e1002178, doi: 10.1371/journal. pgen.1002178.

71. Smith JA. Update on ankylosing spondylitis: current concepts in pathogenesis. Curr Allergy Asthma Rep 2015; 15(1): 489. doi: 10.1007/s11882-014-0489-6.

72. Nicknam MH, Mahmoudi M, Amirzargar AA, Ganjalikhani Hakemi M, Khosravi F, Jamshidi AR. et al. Determination of HLAB27 subtypes in Iranian patients with ankylosing spondylitis. Iran $\boldsymbol{J}$ Allergy Asthma Immunol 2008; 7(1): 19-24. doi: 07.01/ijaai.1924.

73. Ebrahimi Daryani N, Najmi Varzaneh F, Hedayat M, Taher M, Farhadi E, Mahmoudi M. et al. Interleukin-23 receptor single nucleotide polymorphisms in ulcerative colitis. A study in Iranian populations. Clin Res Hepatol Gastroenterol 2014; 38(3): 360-5. doi: 10.1016/j.clinre.2013.12.008.

74. Momenzadeh $\mathrm{P}$, Mahmoudi M, Beigy M, Garshasbi M, Vodjdanian M, Farazmand A. et al. Determination of IL1 R2, ANTXR2, CARD9, and SNAPC4 single nucleotide polymorphisms in Iranian patients with ankylosing spondylitis. Rheumatol Int 2016; 36(3): 429-35. doi: 10.1007/s00296-015-3391-1.

75. Mahmoudi M, Jamshidi AR, Amirzargar AA, Farhadi E, Nourijelyani K, Fallahi S. et al. Association between endoplasmic reticulum aminopeptidase-1 (ERAP-
1) and susceptibility to ankylosing spondylitis in Iran. Iran J Allergy Asthma Immunol 2012; 11(4): 294300. doi: 011.04/ijaai.294300.

76. Azizi E, Massoud A, Amirzargar AA, Mahmoudi M, Soleimanifar N, Rezaei N. et al. Association of CTLA4 gene polymorphism in Iranian patients with ankylosing spondylitis. Journal of Clinical Immunology 2010; 30(2): 268-71, doi: 10.1007/s10875-009-9356-y.

77. Momenzadeh P, Mahmoudi M, Beigy M, Garshasbi M, Vodjdanian M, Farazmand A. et al. Determination of IL1 R2, ANTXR2, CARD9, and SNAPC4 single nucleotide polymorphisms in Iranian patients with ankylosing spondylitis. Rheumatology International 2016; 36(3): 429-35, doi: 10.1007/s00296015-3391-1.

78. JÄRvinen P. Occurrence of ankylosing spondylitis in a nationwide series of twins. Arthritis \& Rheumatology 1995; 38(3): 38183, doi: 10.1002/art.1780380313.

79. Ivanyi P. Immunogenetics of the spondyloarthropathies. Current Opinion in Rheumatology 1993; 5(4): 436-45, doi: 10.1097/ 00002281-199305040-00006.

80. Mahmoudi M, Aslani S, Nicknam MH, Karami J, Jamshidi AR. New insights toward the pathogenesis of ankylosing spondylitis; genetic variations and epigenetic modifications. Modern Rheumatology 2017; 27(2): 198209, doi: 10.1080/14397595.2016. 1206174.

81. Brown MA, Kennedy LG, Macgregor AJ, Darke C, Duncan E, Shatford JL. et al. Susceptibility to ankylosing spondylitis in twins the role of genes, HLA, and the environment. Arthritis \& Rheumatology 1997; 40(10): 182328, doi: 10.1002/art.1780401015.

82. Pedersen O, Svendsen AJ, Ejstrup L, Skytthe A, Harris J, Junker P. Ankylosing spondylitis in Danish and Norwegian twins: occurrence and the relative importance of genetic vs. environmental effectors in disease causation. Scandinavian Journal of Rheumatology 2008; 37(2): 120-26, doi: 10.1080/ 03009740701824613.

83. Generali E, Scirè CA, Favalli EG, Selmi C. Biomarkers in psoriatic arthritis: a systematic literature review. Expert review of Clinical
Immunology 2016; 12(6): 651-60, doi: $\quad 10.1586 / 1744666 x .2016$. 1147954.

84. Grjibovski A, Olsen A, Magnus P, Harris J. Psoriasis in Norwegian twins: contribution of genetic and environmental effects. Journal of the European Academy of Dermatology and Venereology 2007; 21(10): 1337-43, doi: 10. 1111/j.1468-3083.2007.02268.x.

85. Brandrup F, Hauge M, Henningsen K, Eriksen B. Psoriasis in an unselected series of twins. Archives of Dermatology 1978; 114(6): 87478, doi: 10.1001/archderm.114.6. 874.

86. Farber EM, Nall ML, Watson W. Natural history of psoriasis in 61 twin pairs. Archives of Dermatology 1974; 109(2): 207-11, doi:10.1001/ archderm.1974.01630020023005.

87. Duffy D, Spelman L, Martin N. Psoriasis in Australian twins. Journal of the American Academy of Dermatology 1993; 29(3): 42834, doi: 10.1016/0190-9622(93) 70206-9.

88. Lønnberg AS, Skov L, Skytthe A, Kyvik K, Pedersen O, Thomsen S. Heritability of psoriasis in a large twin sample. British Journal of Dermatology 2013; 169(2): 412-16, doi: 10.1111/bjd.12375.

89. Harden JL, Krueger JG, Bowcock AM. The immunogenetics of psoriasis: a comprehensive review. Journal of Autoimmunity 2015; 64: 66-73, doi: 10.1016/j.jaut.2015.07. 008 .

90. Deng Y, Chang C, Lu Q. The inflammatory response in psoriasis: a comprehensive review. Clinical Reviews in Allergy \& Immunology 2016; 50(3): 377-89, doi: 10.1007/ s12016-016-8535-x.

91. Ebers GC. Environmental factors and multiple sclerosis. The Lancet Neurology 2008; 7(3): 268-77, doi: 10.1016/s1474-4422(08)70042-5.

92. Breitling LP, Yang R, Korn B, Burwinkel B, Brenner H. Tobaccosmoking-related differential DNA methylation: $27 \mathrm{~K}$ discovery and replication. The American Journal of Human Genetics 2011; 88(4): 450-57, doi: 10.1016/j.ajhg.2011.03. 003.

93. Allione A, Marcon F, Fiorito G, Guarrera S, Siniscalchi E, Zijno A. et al. Novel epigenetic changes unveiled by monozygotic twins discordant for smoking habits. PloS 
One 2015; 10(6): e0128265, doi: 10.1371/journal.pone.0128265.

94. Ito K, Lim S, Caramori G, Chung K, Barnes P, Adcock I. Cigarette smoking reduces histone deacetylase 2 expression, enhances cytokine expression, and inhibits glucocorticoid actions in alveolar macrophages. The FASEB Journal 2001; 15(6): 1110-12, doi: 10.1096/ fj.00-0432fje.

95. Fetahu IS, Höbaus J, Kállay E. Vitamin D and the epigenome. Frontiers in Physiology 2014; 5, doi: 10.3389/fphys.2014.00164.

96. Niller $\mathrm{HH}$, Wolf $\mathrm{H}$, Minarovits J: Epigenetic dysregulation of the host cell genome in Epstein-Barr virus-associated neoplasia. In: Seminars in cancer biology 2009: 158-64, 19(3), doi: 10.1016/j. semcancer.2009.02.012.

97. Izumi KM, Kieff ED. The EpsteinBarr virus oncogene product latent membrane protein 1 engages the tumor necrosis factor receptorassociated death domain protein to mediate $\mathrm{B}$ lymphocyte growth transformation and activate NF- $\mathrm{BB}$. Proceedings of the National Academy of Sciences 1997; 94(23): 12592-97, doi:10.1073/pnas.94.23. 12592.

98. Riley KJ, Rabinowitz GS, Yario TA, Luna JM, Darnell RB, Steitz JA. EBV and human microRNAs cotarget oncogenic and apoptotic viral and human genes during latency. The EMBO Journal 2012; 31(9): 2207-21, doi: 10.1038/emboj.2012. 63.

99. Germolec D, Kono DH, Pfau JC, Pollard KM. Animal models used to examine the role of the environment in the development of autoimmune disease: findings from an NIEHS Expert Panel Workshop. Journal of Autoimmunity 2012; 39(4): 285-93, doi: 10.1016/j.jaut.2012.05.020.

100. Ngalamika O, Zhang Y, Yin H, Zhao M, Gershwin ME, Lu Q. Epigenetics, autoimmunity and hematologic malignancies: a comprehensive review. Journal of Autoimmunity 2012; 39(4): 451-65, doi: 10.1016/j.jaut.2012.09.002.

101. Selmi C, Leung PS, Sherr DH, Diaz M, Nyland JF, Monestier M. et al. Mechanisms of environmental influence on human autoimmunity: a National Institute of Environmental Health Sciences expert panel workshop. Journal of
Autoimmunity 2012; 39(4): 272-84, doi: 10.1016/j.jaut.2012.05.007.

102. Waddington $\mathrm{CH}$. Canalization of development and the inheritance of acquired characters. Nature 1942; 150(3811): 563-65, doi: 10.1038/ $150563 \mathrm{a} 0$.

103. Gomez-Cabrero D, Almgren M, Sjöholm LK, Hensvold AH, Ringh MV, Tryggvadottir R. et al. Highspecificity bioinformatics framework for epigenomic profiling of discordant twins reveals specific and shared markers for ACPA and ACPA-positive rheumatoid arthritis. Genome Medicine 2016; 8(1): 124, doi: 10.1186/s13073-016-0374-0.

104. Staals RH, Pruijn GJ. The human exosome and disease. In: RNA Exosome. Springer; 2010: 132-42, doi:10.1007/978-1-4419-7841-7_11.

105. Svendsen AJ, Gervin K, Lyle R, Christiansen L, Kyvik K, Junker P. et al. Differentially Methylated Dna regions in Monozygotic Twin Pairs Discordant for rheumatoid arthritis: an epigenome-Wide study. Frontiers in Immunology 2016; 7, doi: 10.3389/fimmu.2016.00510.

106. Kaplan MJ, Lu Q, Wu A, Attwood J, Richardson B. Demethylation of promoter regulatory elements contributes to perforin overexpression in CD4+ lupus $\mathrm{T}$ cells. The Journal of Immunology 2004; 172(6): 3652-61, doi: 10. 4049/jimmunol.172.6.3652.

107. Lu Q, Wu A, Richardson BC. Demethylation of the same promoter sequence increases CD70 expression in lupus $\mathrm{T}$ cells and $\mathrm{T}$ cells treated with lupus-inducing drugs. The Journal of Immunology 2005; 174(10): 6212-19, doi: 10.4049/ jimmunol.174.10.6212.

108. Furukawa H, Oka S, Matsui T, Hashimoto A, Arinuma Y, Komiya A. et al. Genome, epigenome and transcriptome analyses of a pair of monozygotic twins discordant for systemic lupus erythematosus. Human Immunology 2013; 74(2): 170-75, doi: 10.1016/j.humimm. 2012.11.007.

109. Selmi C, Feghali-Bostwick C, Lleo A, Lombardi S, De Santis M, Cavaciocchi F. et al. X chromosome gene methylation in peripheral lymphocytes from monozygotic twins discordant for scleroderma.

Clinical \& Experimental Immunology 2012; 169(3): 253-62, doi: $\quad 10.1111 / \mathrm{j} .1365-2249.2012$. 04621.x

110. Aslani S, Mahmoudi M, Garshasbi M, Jamshidi AR, Karami J, Nicknam MH. Evaluation of DNMT1 gene expression profile and methylation of its promoter region in patients with ankylosing spondylitis. Clinical Rheumatology 2016; 35(11): 2723-31, doi: 10. 1007/s10067-016-3403-x.

111. Lai NS, Chou JL, Chen GC, Liu SQ, Lu MC, Chan MW. Association between cytokines and methylation of SOCS-1 in serum of patients with ankylosing spondylitis. Molecular Biology Reports 2014; 41(6): 377380, doi:10.1007/s11033-014-3242-2.

112. Jiang Y, Wang L. Role of histone deacetylase 3 in ankylosing spondylitis via negative feedback loop with microRNA-130a and enhancement of tumor necrosis factor- $1 \alpha$ expression in peripheral blood mononuclear cells. Molecular Medicine Reports 2016; 13(1): 3540, doi: 10.3892/mmr.2015.4494.

113. Lai NS, Yu HC, Chen HC, Yu CL, Huang $\mathrm{HB}$, Lu MC. Aberrant expression of microRNAs in T cells from patients with ankylosing spondylitis contributes to the immunopathogenesis. Clinical \& Experimental Immunology 2013; 173(1): 47-57, doi: 10.1111/cei. 12089 .

114. Huang J, Song G, Yin Z, Luo X, Ye Z. Elevated miR-29a expression is not correlated with disease activity index in PBMCs of patients with ankylosing spondylitis. Modern Rheumatology 2014; 24(2): 331-34, doi: $\quad 10.3109 / 14397595.2013$. 854077.

115. Sugatani T, Vacher J, Hruska KA. A microRNA expression signature of osteoclastogenesis. Blood 2011; 117(13): $3648-57, \quad$ doi: 10.1182/blood-2010-10-311415.

116. Huang CH, Wei JCC, Chang WC, Chiou SY, Chou CH, Lin YJ. et al. Higher expression of whole blood microRNA-21 in patients with ankylosing spondylitis associated with programmed cell death 4 mRNA expression and collagen cross-linked C-telopeptide concentration. The Journal of Rheumatology 2014; 41(6): 110411, doi: 10.3899/jrheum.130515.

117. Lønnberg AS, Skov L, Duffy DL, Skytthe A, Kyvik KO, Pedersen OB. et al. Genetic factors explain variation in the age at onset of Rheum. Res., Vol. 3, No. 2, Apr. 2018 
Aslani et al.

psoriasis: a population-based twin study. Acta Dermato-Venereologica 2016; 96(1): 35-38, doi: 10.2340/ 00015555-2171.

118. Gervin K, Vigeland MD, Mattingsdal M, Hammer $\varnothing \mathrm{M}$, Nygård $\mathrm{H}$, Olsen AO. et al. DNA methylation and gene expression changes in monozygotic twins discordant for psoriasis: identification of epigenetically dysregulated genes. PLoS Genetics 2012; 8(1): e1002454, doi: 10.1371/ journal.pgen.1002454.

119. Lønnberg AS, Skov L, Skytthe A, Kyvik KO, Pedersen OB, Thomsen
SF. Smoking and risk for psoriasis: a population-based twin study. International Journal of Dermatology 2016; 55(2): e72-78, doi: $10.1111 /$ ijd.13073.

120. Pedersen OB, Svendsen AJ, Ejstrup L, Skytthe A, Junker P. On the heritability of psoriatic arthritis. Disease concordance among monozygotic and dizygotic twins. Annals of the Rheumatic Diseases 2008; 67(10): 1417-21, doi: 10.1136/ard.2007.078428.

121. Ng J, Tan AL, McGonagle D. Unifocal psoriatic arthritis development in identical twins following site specific injury: evidence supporting biomechanical triggering events in genetically susceptible hosts. Annals of the Rheumatic Diseases 2015; 74(5): 948-49, doi:10.1136/annrheumdis2014-206784.

122. Castelino M, Eyre S, Moat J, Fox G, Martin P, Ijaz U. et al. The skin microbiome in psoriatic arthritis: methodology development and pilot data. The Lancet 2015; 385: S27, doi: 10.1016/s0140-6736(15)603427. 